\title{
KENOVIAN (Dzovinar), TRONCHET (Guillaume) (dir), La Babel étudiante, la Cité internationale universitaire de Paris (1920-1950)
}

Rennes, Presses universitaires de Rennes, 2013. [Préface de Robert Franck, mise en perspective de Victor Karady]

\section{Chantal Verdeil}

\section{OpenEdition}

Journals

Édition électronique

URL : https://journals.openedition.org/histoire-education/3098

DOI : 10.4000/histoire-education.3098

ISSN : 2102-5452

Éditeur

ENS Éditions

Édition imprimée

Date de publication : 31 décembre 2015

Pagination : 128-131

ISSN : 0221-6280

Référence électronique

Chantal Verdeil, « KENOVIAN (Dzovinar), TRONCHET (Guillaume) (dir), La Babel étudiante, la Cité internationale universitaire de Paris (1920-1950) », Histoire de l'éducation [En ligne], 144 | 2015, mis en ligne le 31 décembre 2015, consulté le 20 mai 2021. URL : http://journals.openedition.org/histoireeducation/3098; DOI : https://doi.org/10.4000/histoire-education.3098

Ce document a été généré automatiquement le 20 mai 2021.

(c) Tous droits réservés 


\section{KENOVIAN (Dzovinar), TRONCHET (Guillaume) (dir), La Babel étudiante, la Cité internationale universitaire de Paris (1920-1950)}

Rennes, Presses universitaires de Rennes, 2013. [Préface de Robert Franck, mise en perspective de Victor Karady]

\section{Chantal Verdeil}

\section{RÉFÉRENCE}

KENOVIAN (Dzovinar), TRONCHET (Guillaume) (dir), La Babel étudiante, la Cité internationale universitaire de Paris (1920-1950), Rennes, Presses universitaires de Rennes, 2013. [Préface de Robert Franck, mise en perspective de Victor Karady]

1 Fruit d'un colloque organisé en 2010 à l'occasion du versement des archives de la Fondation nationale Cité internationale universitaire de Paris aux Archives nationales, cet ouvrage se présente comme le premier jalon d'une synthèse historique à venir portant sur la Cité internationale universitaire de Paris. Il s'en tient aux trente premières années (une génération) de ce vaste campus (aujourd'hui un parc de 34 hectares abritant une quarantaine de "maisons", autrement dit de résidences étudiantes) qui constitue un lieu unique en France : une « ville » dans la ville aux portes de Paris. Jusqu'ici ce sont surtout ses pavillons à l'architecture soignée, signée parfois de noms prestigieux qui ont retenu l'attention. La Cité, pourtant au cœur des politiques universitaires nationales et internationales, n'a que peu intéressé les historiens. Avec son livret photographique (dont les clichés sont issus des archives susmentionnées), ses repères biographiques des principaux fondateurs, administrateurs et mécènes de la Cité, sa bibliographie établie par Dzovinar Kevonian, ses pistes de recherches esquissées 
par tel ou tel contributeur, ce livre ne se contente pas de faire le point sur les connaissances actuelles, il sonne comme un appel à de nouveaux travaux.

2 Les contributions, classées grosso modo en ordre chronologique, reviennent d'abord sur les circonstances de la création de la Cité universitaire. Avec plus de 17000 étudiants en 1913, et plus de 3000 étrangers dès 1910, la capitale française peut s'enorgueillir d'être une des villes d'Europe qui concentre le plus d'étudiants dont de très nombreux étrangers. Leur présence témoigne du rayonnement des établissements supérieurs parisiens, un rayonnement entretenu à l'époque au nom de l'impérialisme culturel. Ces étudiants toujours plus nombreux, il faut les loger, ce que le développement de l'enseignement supérieur et la hausse du prix des hôtels du Quartier latin rendent de plus en plus difficile. Au tout début du XXe siècle, les initiatives privées, parfois confessionnelles ou étrangères, se multiplient pour répondre à cette demande (P. Moulinier). Cette crise du logement et la volonté d'attirer les étudiants étrangers sont aussi les principaux arguments évoqués pour justifier la cession de l'État à l'université de Paris d'un terrain de 9 ha situé sur la «zone » d'habitats informels installés dans l'espace laissé libre par le démantèlement des anciennes fortifications, afin d'y créer une résidence universitaire à l'anglo-saxonne en 1919. À ces préoccupations françaises, sociales et impériales, s'ajoutent très vite des idéaux pacifistes puisque dès 1921, le recteur Paul Appell voit dans ce projet de résidence universitaire un facteur « de la bonne harmonie des élites internationales» (cité p. 67). Il n'est pourtant pas mené à bien par la puissance publique, mais par une fondation privée dont les statuts sont approuvés en 1925, non pas financé sur les deniers de l'État, mais par de généreux mécènes, dont Émile Deutsch de La Meurthe, patron d'un vaste complexe industriel de raffinage pétrolier, figure de la philanthropie juive et grand mécène de la $\mathrm{III}^{\mathrm{e}}$ République. Sous la houlette de son premier président, André Honnorat, lui même influencé par l'international mind américain, la Cité universitaire s'assigne rapidement une "mission universelle quasi mystique de construction de la paix mondiale » (G. Tronchet, p. 81), bien en phase avec «l'esprit de Genève ». L'œuvre qui sort alors de terre ne relève pas seulement de la diplomatie culturelle (celle du Quai d'Orsay) ou universitaire (portée par le ministère de l'Instruction publique), comme le montre G. Tronchet, elle s'inscrit à la croisée de préoccupations nationales et d'idéaux universels, d'une politique publique et d'initiatives privées, dans un cadre parisien et français fécondé par les apports étrangers. Pendant l'Entre-deux-guerres, elle bénéficie $\mathrm{du}$ développement des œuvres universitaires: logements, restaurant universitaire bientôt installé dans la Maison internationale ouverte en 1936, pavillon médical établi grâce à Charles-Louis Dreyfus (N. Manikatis). Elle offre enfin un cadre aux sociabilités étudiantes formelles et informelles à travers les activités sportives, intellectuelles, et artistiques qu'elle organise ou les espaces qu'elle met à leur disposition (parc, cuisines partagées), le tout dans l'objectif de favoriser cette interconnaissance qui est au cœur de son projet pacifiste (F. Séréni). Ces multiples ancrages, nationaux, internationaux, transnationaux lui permettent de traverser le second conflit mondial sans trop de dommage (la plupart de ses bâtiments de la Cité sont pourtant occupés et dégradés). À mille lieues de la rhétorique nationaliste de l'État français, la Cité n'est pas très éloignée de son projet de régénération morale et physique qui lui vaut une relative protection des autorités de l'État (D. Kévonian). universitaire. Paradoxalement, plusieurs figures de l'Italie fasciste dont l'idéologie 
nationaliste et totalitaire se situe pourtant à l'exact opposé des engagements transnationaux et démocratiques de la Cité, s'y intéressent. G. Gentile, considère avec intérêt cet espace où le régime pourrait faire reconnaître son génie. Cette curiosité s'émousse dans les années 1930, quand la politique italienne se fait plus sectaire et plus agressive (E. Signori). Le cas de la Belgique permet d'évoquer un de ces couples de mécènes qui firent la Cité, Hubert Birmans, self-made-man qui a fait fortune dans les chemins de fer, et son épouse Berthe Lapôtre, à l'origine du pavillon qui porte leur nom, inauguré en 1927. La maison, d'abord destinée aux ressortissants belges s'ouvre très vite aux Luxembourgeois, contraints de quitter leur pays, qui n'a pas d'université, pour poursuivre leurs études. A partir de 1947, elle commence timidement à accueillir des filles (S. Jaumain et $\mathrm{P}$. Van Den Dungen). La présence américaine, évoquée à travers l'épisode de l'occupation de la Cité par l'armée américaine de novembre 1944 à septembre 1945, mériterait de plus amples développements, tant les influences américaines furent grandes à la fois sur son organisation (sur le modèle des campus nord-américains) et son mode de financement (le mécénat). La Fondation des ÉtatsUnis, largement financée par Homer Gage et sa femme Mabel, fut inaugurée en 1930 et servit de centre de formation pour des soldats étudiants de 1945 à 1946 avant d'être rendue à la vie civile (E. Capdevila). L'ouvrage se clôt par un court article de Fabien Oppermann sur la richesse du fonds des archives de la Cité.

4 Outre une meilleure connaissance de la vie étudiante (conditions de vie, sociabilité, recrutement, carrière), la Cité, avec son triple ancrage national, international et transnational, constitue un objet singulier susceptible de nourrir des recherches sur les milieux internationaux, dont elle fut, par ses mécènes comme par ses étudiants, un incontestable creuset. L'histoire de ses femmes, épouses de mécènes et mécènes ellesmêmes, étudiantes ou directrices de maison, reste à écrire. Les différents pavillons devraient susciter des travaux sur leur construction, leur place dans les diplomaties des pays concernés, mais aussi dans leur histoire nationale, où certains, comme la maison du Cambodge ou de l'Iran, se sont illustrés. Reste aussi à poursuivre cette histoire audelà des années 1950 jusqu'à... aujourd'hui. Gageons que cet ouvrage constituera un jalon utile dans cette vaste entreprise. Avis aux historiens : le chantier est ouvert. 